\title{
Solar cooling design: a case study
}

\author{
S. Grignaffini \& M. Romagna \\ Department of Astronautic, Electric and Energetic Engineering, \\ "Sapienza", University of Rome, Italy
}

\begin{abstract}
Throughout the years various methods have been used for heat prevention and indoor temperature control in the summer in Mediterranean, tropical and subtropical countries. The alternative cooling strategies are based on various passive and low energy cooling technologies for protection of the buildings via design measures or special components to moderate the thermal gains, or to reject the excess heat to the ambient environment. All these techniques aim to reduce summer cooling loads and electricity demand for air conditioning. During the summer, in Mediterranean, tropical and subtropical countries, the demand for electricity increases because of the extensive use of heating ventilation air conditioning (HVAC) systems, which increase the peak electrical load, causing several problems in the electricity supply.

The cooling of buildings can be efficiently addressed by referring to the concepts of energy efficiency and use of renewable sources. A particular method is the use of absorption chillers capable of using the thermal energy for producing chilled water. So, an integration of the system with renewable energy is possible: the absorption chiller can be supplied with thermal energy captured by solar collectors. This last mode of operation leads to the solar cooling systems.

The use of solar energy to drive cooling cycles for space conditioning of most buildings is an attractive concept, since the cooling load coincides generally with solar energy availability and therefore the cooling requirements of a building are roughly in phase with the solar radiation. Moreover, they are energy efficient and environmentally safe.

The purpose of this paper is to describe a solar cooling system to be installed on the roof of a building in Rome, the headquarters of the State Monopoly of Italy.
\end{abstract}


The medium sized power plant is composed of the following components:

- solar collectors;

- thermal storage;

- absorption chiller;

- cooling tower;

- auxiliary system backup.

Solar cooling design will be based on a dynamic simulation in TRNsys. Keywords: solar cooling, transient state calculation, TRNsys.

\section{Introduction}

Buildings with a life of over 15-20 years are characterized mostly by poor energy performance. The greater the length of the buildings, the lower their thermal-energy performance, in most cases. The study of their rehabilitation is now an issue technically and scientifically more than ever. Computing systems used today are usually full of uncertainties relying on overly simplified and analytically weak models. The most advanced computing systems in transition, however, are closest to reality and allow for modelling the behaviour of buildings in more detail with step by step analysis and also non-linear correlations.

\subsection{Case study description}

The research work carried out by the authors has as the subject building, the site of the Directorate General of AAMS (Monopoly Administration State) who are charged at the national level to regulate the public gaming sector and control the production, distribution, sale and duties of tobacco products. The building is located in the Centre of Rome and is composed of two connected bodies. The smaller building overlooks the square and has a significant historical value, dating back to the second half of the 1800s. The other part, the larger one is the administrative headquarters of AAMS - a newer building built in the 1960s. So, we will call the two buildings, for convenience, a historic building and modern building, respectively.

The historic building is divided into a basement at an altitude of about $-5 \mathrm{~m}$ from the ground and 4 floors above ground to a height of about $22 \mathrm{~m}$. Architecturally, the building consists of offices overlooking the square and a long corridor, with a substantially rectangular plan of maximum size $17.1 \mathrm{x}$ $74.1 \mathrm{~m}$ and extension plan of approximately $1030 \mathrm{~m}^{2}$. This building has a volume of $20000 \mathrm{~m}^{3}$ and an $\mathrm{S} / \mathrm{V}$ ratio (Surface/Volume $\left[\mathrm{m}^{2} / \mathrm{m}^{3}\right]$ ) equal to $0.29 \mathrm{~m}^{2} / \mathrm{m}^{3}$ with different floor heights, and then different floor volumes. The modern building is divided into two underground floors and 7 floors above ground to a total height of about $24 \mathrm{~m}$. The area of the part used for offices (i.e. excluding stores and technical rooms) is about $3040 \mathrm{~m}^{2}$. This second volume of $70,300 \mathrm{~m}^{3}$ has an $\mathrm{S} / \mathrm{V}$ ratio equal to $0.28 \mathrm{~m}^{2} / \mathrm{m}^{3}$. The entire building complex is served from the same thermal power plant and has a total area of $30,000 \mathrm{~m}^{2}$. The two buildings were built at different times so the thermal performance 
characteristics are significantly different. The historic building has small openings made in the main walls (bearing masonry): the wall thickness is about $1.5 \mathrm{~m}$ in the basement up to $0.80 \mathrm{~m}$ on the top floor. The modern building is characterized by large glass surfaces and walls with no insulation layer. This characteristic is the fundamental cause of its natural tendency to overheating in summer. The buildings have a north-west orientation and the angle between the line orthogonal to the main facade of the historic building and direction of the north is $66^{\circ}$ (Figure 1). A precise evaluation of the contributions from solar radiation through the glass surfaces is not easy because the building is located in a densely urbanized district where neighbouring buildings with their shadows affect the exposure.

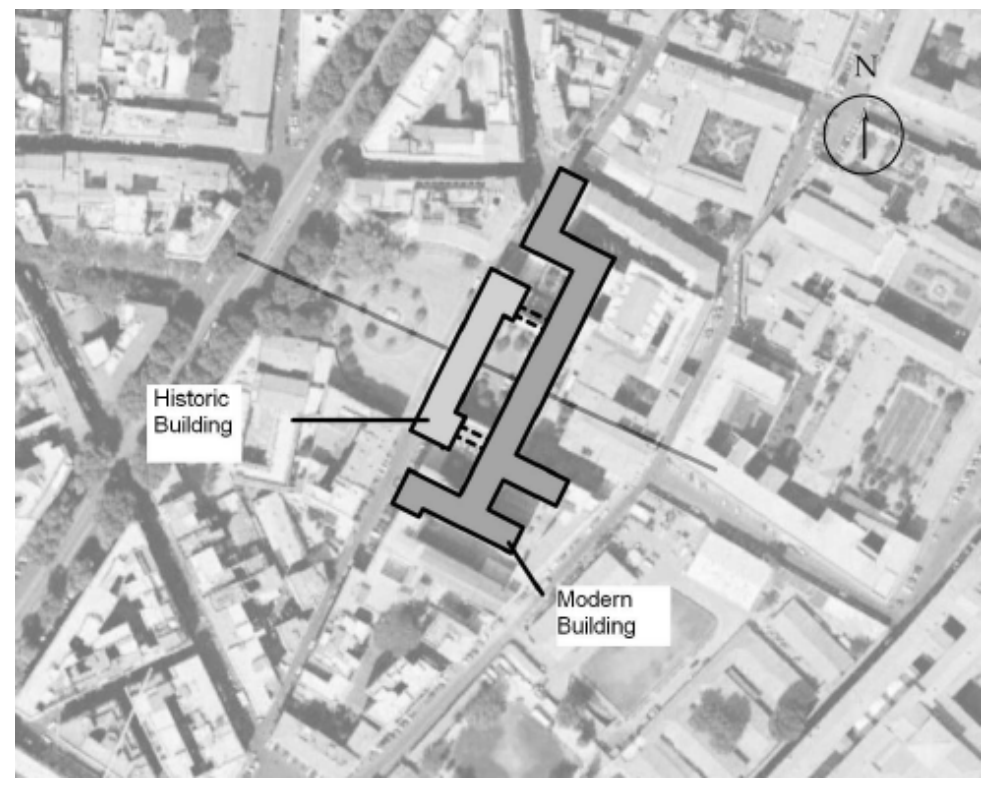

Figure 1: Case study: building orientation and its position in urban surroundings of Rome.

\section{Calculation methodology and transient state modelling}

The main purpose is to verify analytically the possibility of installing a solar thermal system that integrates the current internal temperature control systems. The project idea is to install a field of solar panels directly to the integration of the winter heating with an absorption machine for the construction of a solar cooling system for summer cooling. The calculation will be strictly made by using the most advanced methods for transient state calculation through the use of TRNsys code. 
The study begins by collecting data on building energetic consumption, in order to know, through energy audit, the heating energy required (i.e. by a thermographic survey (Figure 2.))

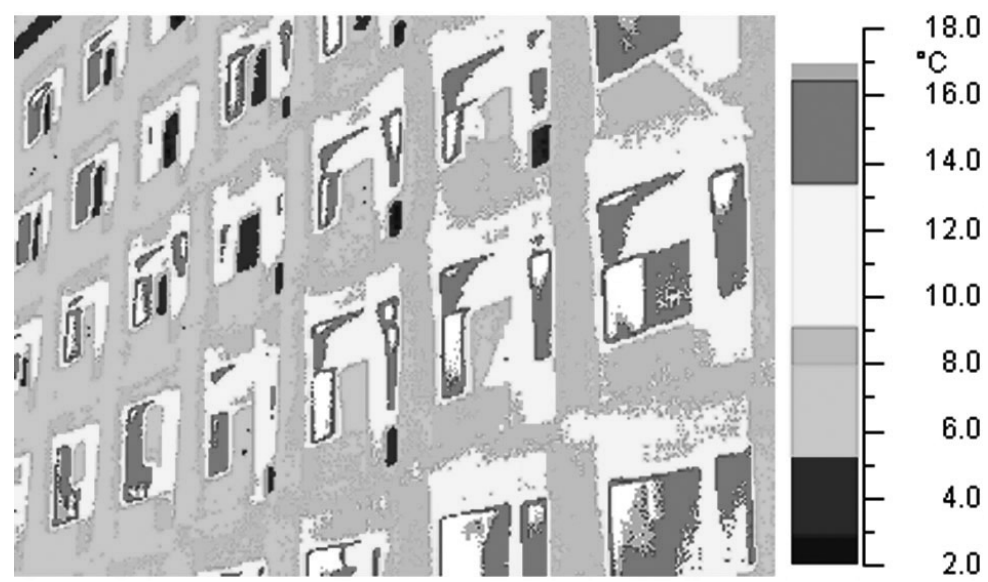

Figure 2: $\quad$ Thermographic survey: building main facade.

A TRNsys model of the building will be created and it will be calibrated through the undetermined parameters in the calculation data of the diagnosis previously carried out. The output of thermal energy obtained, representing the energy demands at the time, will be the starting point for the operations of building energy upgrading. The model is based on statistical data appropriately averaged for the characterization and sunny weather for the site of the building complex studied.

\subsection{Energy audit}

Starting from the data supply of the main sources of energy is recovered through a reverse process of calculating the determination of energy needs done and not supposed to reach stable thermal conditions required for the entire calendar year. Where possible, values were averaged over several years before being processed, in order to obtain statistically acceptable values and lack of physiological fluctuations related to climate and other occasional events.

By studying these systems, heating demand was related to the consumption of natural gas marked on the meter installed before the thermal system. The regression was obtained by the following formula:

$$
\mathrm{Q}=\mathrm{CPc} \eta_{\mathrm{t}}
$$

with $\mathrm{Q}$ being the heat energy required in a given period of time when $\mathrm{C}\left[\mathrm{m}^{3}\right]$ of natural gas with calorific value (Pc) of gas equal to $34,541 \mathrm{~kJ} / \mathrm{m}^{3}$ are burned. The processing yield $\eta_{\mathrm{t}}$ is shown on the manufacturer's data sheets of the various thermal machines unless an empirical reduction factor to take into account other losses in yield of system. In Tables 1 and 2, the results of the regression and the values of the energy needs of the volume index are reported. 
A process conceptually similar was followed for cooling demand, but by analyzing the data of electricity consumption. In this case the values are given as the sum total consumption and hence we must extrapolate from other links the consumption of installed chillers.

The correlations proposed and exploited are those with average maximum and minimum temperatures and the brightness values of the ground.

Figure 3 shows the comparison with the temperatures, where it shows a clear correlation with consumption during the summer.

Table 1: Building heating demand.

\begin{tabular}{|c|c|c|c|}
\hline Use & Gas Use[m $3 /$ year] & Energy $[\mathbf{k W h} / \mathbf{y e a r}]$ & $\begin{array}{c}\text { Index }\left[\mathbf{k W h} / \mathbf{m}^{\mathbf{3}}\right. \\
\text { year] }\end{array}$ \\
\hline Heating & 167.557 & 1.543 .361 & 1,35 \\
\hline Hot Water & 3.952 & 36.781 & 18,1 \\
\hline
\end{tabular}

Table 2: $\quad$ Building cooling demand.

\begin{tabular}{|c|c|c|c|}
\hline Use & $\begin{array}{c}\text { Electricity } \\
{[\mathbf{k W h} / \text { year }]}\end{array}$ & $\begin{array}{c}\text { Thermal } \\
\text { Energy }[\mathbf{k W h} / \mathbf{y e a r}]\end{array}$ & $\begin{array}{c}\text { Index }\left[\mathbf{k W h} / \mathbf{m}^{\mathbf{3}}\right. \\
\text { year }]\end{array}$ \\
\hline Cooling & 295.887 & 887.725 & 10,1 \\
\hline
\end{tabular}

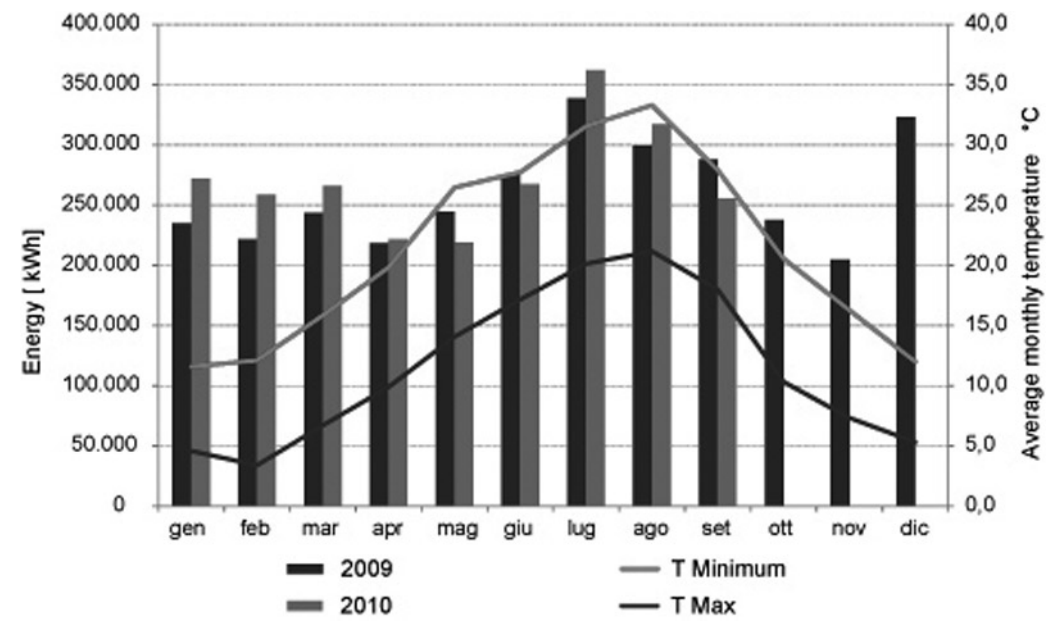

Figure 3: Electricity consumption and temperature correlation.

During the months of no operation of the temperature control system, it is assumed that consumption is linked exclusively to other uses. As for gas, Table 2 shows the annual data analysis for the electricity used for the cooling system.

\subsection{TRNsys model}

TRNsys building model is realized by connecting types identified by a number: 89, 16, 69, 34, 65, 25, 24 and Type 56 "Multi-Zone Building." More types will be added for the specific project along with various calculator forms (Figure 4). 
The base model is realized through improved calibration data obtained from the energy audit, in order to determine infiltrations and thermal bridges and to verify the effects of shade from surrounding buildings and the temperature of basements that are not temperature controlled and the effects of shielding on the windows fixed on the top floor. Once models were built and calibrated, we can analyze the output results of the TRNsys solver. Among the many outputs of the calculation, the most interesting for the planning phase and the interpretation of the thermal behaviour of the building are the temperatures and thermal inputs delivered every hour. Figure 5 represents the output of the two buildings of the

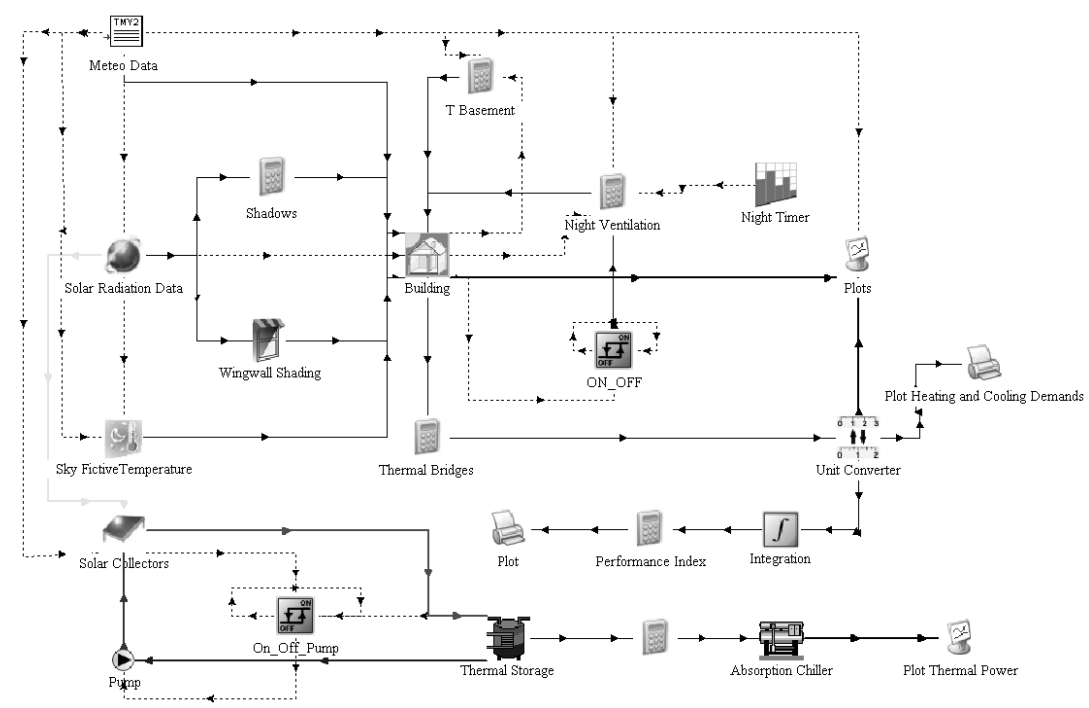

Figure 4: $\quad$ TRNsys model of case study building.

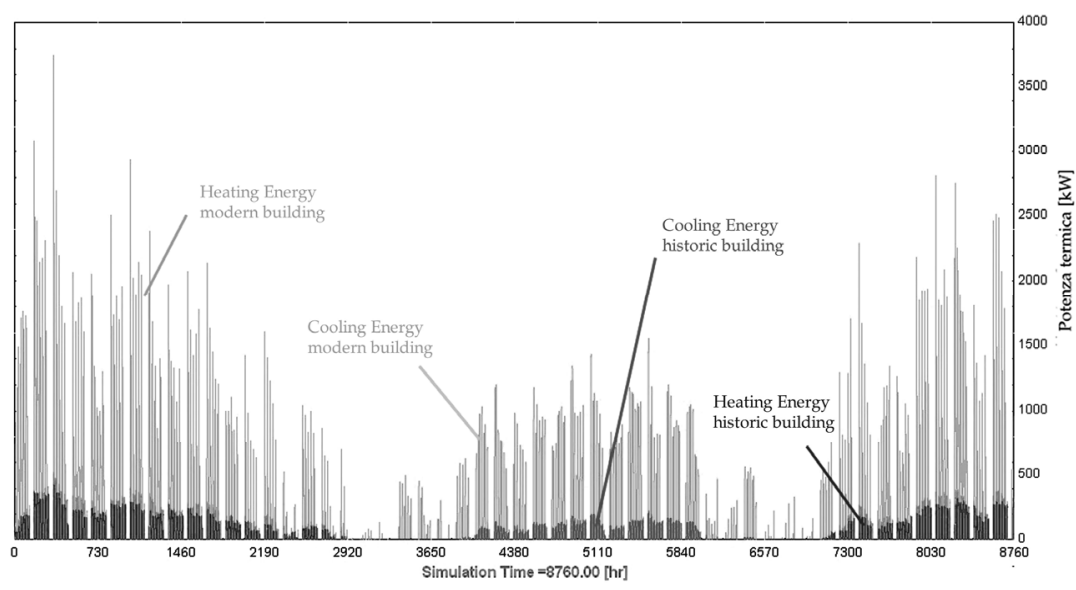

Figure 5: Annual building energy rate: TRNsys model outputs. 
thermal-generated model implemented for the pre-intervention situation. The heating rates have developed quite differently from these and there is a heating requirement proportionately higher in winter than in summer, a sign in a temperate climate (such as Rome climate), of a poor energetic quality of the building. The peak intensities obtained from the calculation is about $4 \mathrm{MW}$ and $2 \mathrm{MW}$ for heating and cooling while the medium ones are, respectively, $916 \mathrm{~kW}$ and $616 \mathrm{~kW}$. Detailed analysis shows a more constant demand for the historic building with greater thermal inertia and lower glass surfaces.

\section{Energy improvement and energy audit in transient state}

Once the model of the building developed, the possible energy improvement has been proposed and verified.

By the use of a TRNsys model it was possible to evaluate, in a more complex way, every single intervention verifying peak hours and seasonal averages of the thermal powers and obtaining objective data on the summer behaviour of the system for the design of solar cooling.

Interactions between the various interventions and the non-linearity of their combination were studied too. Each intervention highlighted specific effects on the heating requirements of the building by changing the proportionality between energy demand and the demand for heating and cooling. There are some traditional interventions such as lowering the transmittance of the dispersants' opaque walls (through the provision of insulation) and the replacement of windows with greater efficiency which lead to a reduction of heating requirements only during wintertime.

During summertime, however, the demand remains constant, since, as expressed numerically by calculating the ratio of solar gains and losses through the envelope remains constant. In other words, the building naturally stores energy in the absence of cooling systems. Without dwelling too much on this part, Table 3 shows (text indexes derived from a weighted average on volumes) the results obtained with the redevelopment of the dispersant structures chosen:

\subsection{Modern building}

- provision of an insulating layer of about $4 \mathrm{~cm}$ for external walls and of about $6 \mathrm{~cm}$ for the floors. (heat capacity of $700 \mathrm{~J} / \mathrm{kg} \mathrm{K}$, thermal conductivity of $0.18 \mathrm{~kJ} / \mathrm{h} \mathrm{m} \mathrm{K}$, density $80 \mathrm{~kg} / \mathrm{m}^{3}$ )

- replacement of single glazed (thickness $4 \mathrm{~mm}$, U-value 5.68, G-value of $0.855,0.83 \mathrm{~T}$-sol, sol-Rf 0.075 ) of all windows with double glazing (416-4 mm thickness, $\mathrm{U}$-value 2.83 , G-value of $0.755,0.693 \mathrm{~T}$-sol, sol-Rf 0.126 .

\subsection{Historic building}

- provision of an insulating layer of about $4 \mathrm{~cm}$ for external walls and of about $6 \mathrm{~cm}$ for the floors. 
Table 3: Performance indexes after structural interventions of energy improvement $\left[\mathrm{kWh} / \mathrm{m}^{3}\right.$ year].

\begin{tabular}{|c|c|c|c|}
\hline Index & Historic Building & Modern Building & Total \\
\hline Heating Index & 12,8 & 9,5 & 10,3 \\
\hline Cooling Index & 4,0 & 8,6 & 7,5 \\
\hline
\end{tabular}

In order to reduce the summer demand in the modern building an innovative intervention is proposed: a building night cooling with 3 air changes per hour from 1 to 6 o'clock AM. With this intervention, the cooling index decreases from 8.6 to $6.1 \mathrm{kWh} / \mathrm{m}^{3}$ year.

Overall, the redevelopment leads to a lowering of the thermal energy needs both in summer and wintertime. The energy for heating is equal to $849,300 \mathrm{kWh} /$ year while for cooling one is $465,450 \mathrm{kWh} /$ year. Please note that the choice of the redevelopment was also made in anticipation of the installation of a solar cooling system. The modulation and the proportionality of the application in heating and cooling are essential for the success of the intervention of integration with solar system.

\section{Integration with solar heating system: transient state calculation}

Once the values of the thermal demand of the building have been obtained it is possible to design the system integration of solar energy. The system has the space to install the roof level (about $3000 \mathrm{~m}^{2}$ ) of the modern building where collectors for the capture of solar energy can be installed. The system involves the coupling of an absorption chiller to provide integration with the system even during the summertime. Installations can be integrated in both heating and cooling system, reducing the depreciation costs for equipment and collectors. Making use of the TRNsys code we can get a track time of supply thermal energy depending on the design parameters. The calculation of the solar system was held in parallel to the building. The parameters used in the calculation affects the solution but do not alter the development.

\subsection{Solar system model}

The design of the system is so integrated with respect to the transient calculation. The main parameters to determine the type of collectors is to be installed, orientation, tilt angle and their extension. For the installation of solar-cooling the main parameter is the cooling capacity of the absorption chiller. Please note we are still in pre-dimensioning, the final calculation will be done as a test, once all the parameters of the system components are known and entered.

The proposed plant collectors have arranged coverage with azimuth angle equal to $24^{\circ}$ south and $35^{\circ}$ tilt angle.

The following statement, even if not energetically optimal, was chosen for optimal energy efficiency issues of installation. Each collector has an absorber 
area of $2.257 \mathrm{~m}^{2}$ and the efficiency curve with parameters $\mathrm{a}_{0}=0.8$, $\mathrm{a}_{1}=2.02 \mathrm{~W} / \mathrm{m}^{2} \mathrm{~K}, \mathrm{a}_{2}=0.0046 \mathrm{~W} / \mathrm{m}^{2} \mathrm{~K}^{2}$.

The system consists of rows of collectors connected in parallel and in series to ensure that the design conditions imposed by the manufacturer for maximum temperatures of the heat transfer fluid circulating in the solar and flow into the circulation. The exchange occurs in a thermal storage tank. As a first approximation, without knowing the specifics of the absorption chiller to install itself as a constant average performance standard which could facilitate the predimensioning and choice of range of collectors to be installed. This determines the ratio between the total heat demand and the amount of energy obtained from solar energy. Figure 6 shows the revised output in Excel for the amount of solar collectors to pre-dimensioning of 400 collectors for a total extension of $900 \mathrm{~m}^{2}$. This choice is not direct and must take into account various aspects. We must consider not only the integral values of energy exchanged but also the contemporary and the respective proportionality between energy supply and demand. Solar energy expressing as heat cannot be stored temporarily for periods of time to allow $100 \%$ coverage without oversizing plant consistently enough to make the management too difficult as well as uneconomic during periods of inactivity. In Figure 6, the jump between about 3000 and 7000 hours is due to the transition between heating and cooling, and then the intervention of the absorption chiller, which reduces the efficiency of the energy process.

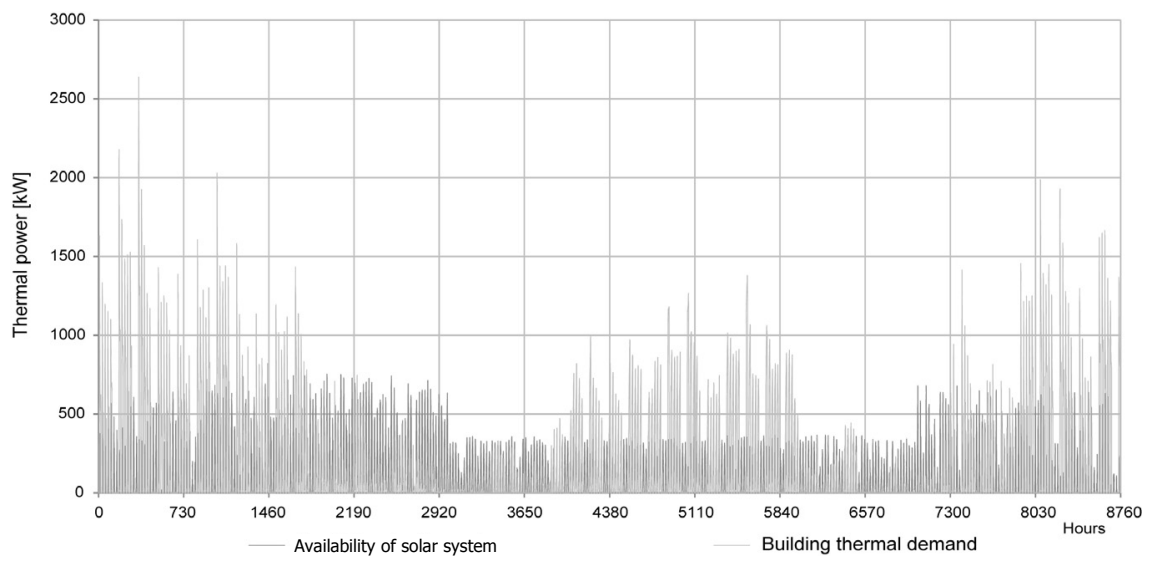

Figure 6: Solar system: TRNsys model outputs.

\subsection{Transient state sizing}

Through the calculation carried out with TRNsys transient it was possible to determine the incident solar radiation to the panel that was equal to $4021 \mathrm{kWh} /$ year. This energy is converted into heat by the collectors with an average of $3024 \mathrm{kWh} /$ year with an average efficiency of about $75 \%$. It should be emphasized again that the choice of interventions to achieve redevelopment is key to achieving energy proportionality in the application for you to have a 
balanced sizing of the system. The energy required for cooling should be a little lower (about $-20 \%$ ) than that required for heating. The state before the redevelopment of this building leaves no room for action in the absence of balanced choices of action structures. Figures 7 show, respectively, the behaviour of interaction for a typical week in winter and summer. The main evidence of the work is that a good sizing of the solar cooling in winter should be characterized by values of coverage throughout the day not far in excess of the minimum demand to prevent excessive heat storage. In summer, however, as can be appreciated from the figure, the system transient calculation takes a clear step in the evolution of supply and demand being the second curve almost proportionally contained in the first.

Table 4: $\quad$ Energy improvement: summary table.

\begin{tabular}{|c|c|c|c|c|}
\hline & Initial Value & $\begin{array}{c}\text { Solar System } \\
\text { Contribution }\end{array}$ & Final Value & Reduction \% \\
\hline Heating $[\mathrm{kWh} /$ year] & 1.529 .230 & 276.805 & 574.295 & $-62,5$ \\
\hline Cooling $[\mathrm{kWh} /$ year] & 655.650 & 187.407 & 483.593 & $-26,5$ \\
\hline Heating Index[kWh/m ${ }^{3}$ year $]$ & 18,4 & & 6,9 & \\
\hline Cooling Index $\left[\mathrm{kWh} / \mathrm{m}^{3}\right.$ year $]$ & 8,2 & & 5,8 & \\
\hline
\end{tabular}

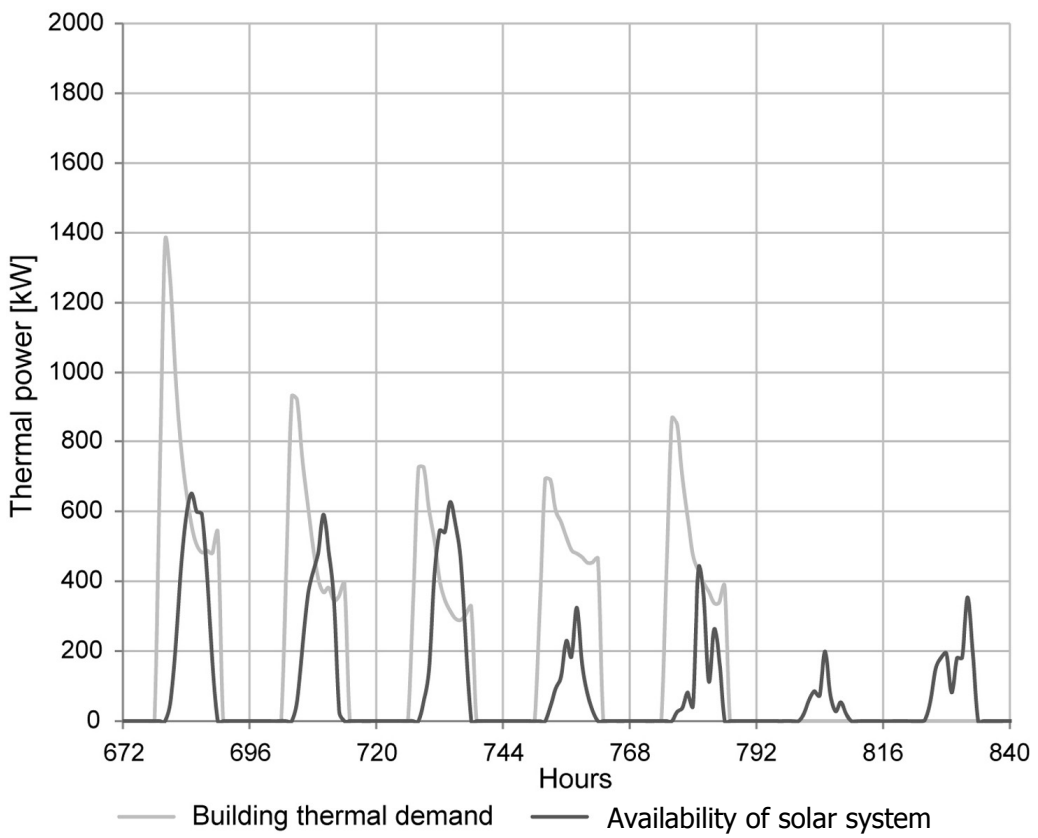

Figure 7: Solar system: TRNsys model outputs on a typical winter day. 


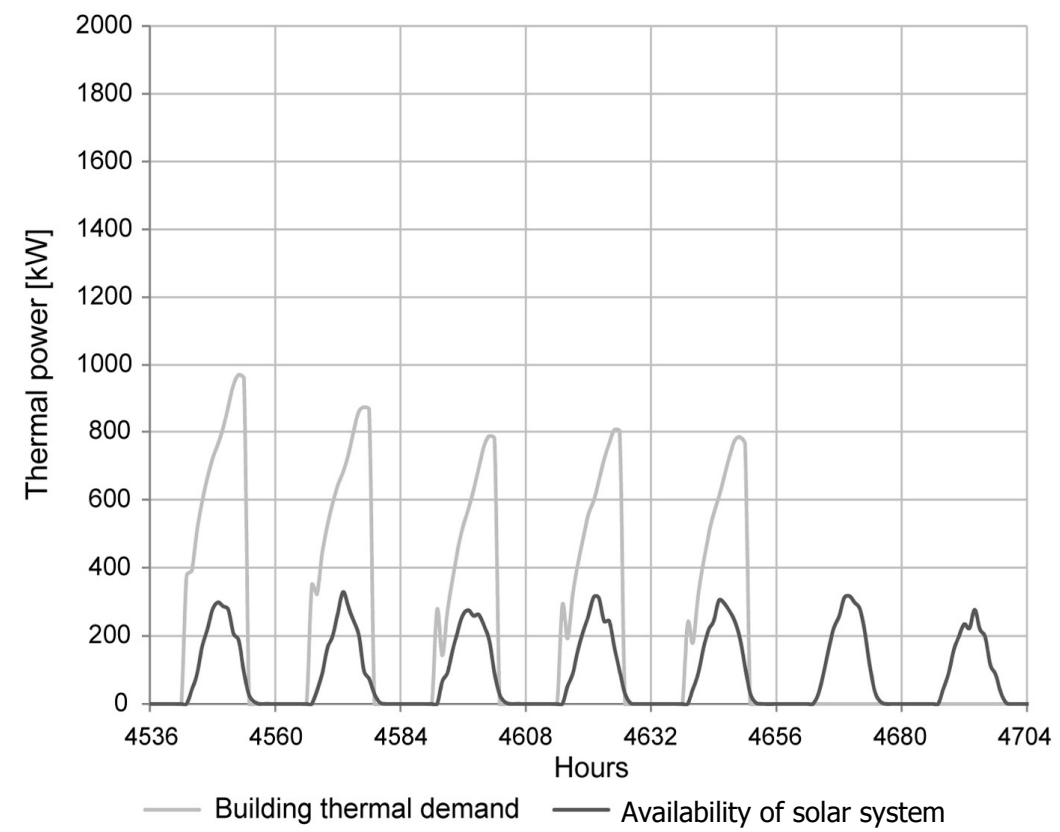

Figure 8: $\quad$ Solar system: TRNsys model outputs on a typical summer day.

Availability of these data also reflect the fact that while in winter the heat engines at maximum power demand are reduced by the presence of the installation of solar cooling in summer with a correspondence between peak demand and power available, they have an interesting decline from 1.4 MW to $1 \mathrm{MW}$ with a reduction of about $25 \%$. Among the outputs of TRNsys and the revision in Excel extracts, the peak value of energy absorption chiller for the collector array adopted in our case is about $360 \mathrm{~kW}$. The system allows the total elimination of a domestic hot water system, the heat being abundantly available in excess in relation to energy needs for this use.

\section{Conclusions}

The modelling phase is the only one that allows a calculation of real variables and the integration of thermal energy plants and facilities. An analysis of data obtained from the dynamic calculation can determine, in fact, the energy actually absorbed by the system to supplement the application. Table 5 shows the global indexes for the building following the intervention of integration through renewable sources. The energy derived from the table is considered as deductible contribution to the energetic needs being free gains for the building.

\section{References}

[1] Henning, H.-M. (2004) Solar-Assisted Air-Conditioning in Building A Handbook for Planners. Springer-Verlag/Wien. 
[2] University of Wisconsin-Madison (2004) TRNSYS 16: A TRaNsient SYstem Simulation program - Volume 5 Mathematical reference, University of Wisconsin-Madison.

[3] Hellmann, H.-M. and Ziegler, F. (1999) Simple absorption heat pump modules for system simulation programs, ASHRAE Transactions 105.

[4] Duffie, J. A. and Beckman, W. (2006), Solar Engineering of Thermal Processes, Wiley-Interscience. 